\title{
Effect of carbon and cold rolling on the latent heat upon $\varepsilon \rightarrow Y$ transformation in metastable Fe-Mn alloys
}

\author{
M. Murasov ${ }^{\mathrm{a} 1}$, L. Duprez ${ }^{2}$, B. Verlinden ${ }^{1}$, J. V. Humbeeck ${ }^{1}$ \\ ${ }^{1}$ Department MTM, KU-Leuven, 3001 Leuven, Belgium \\ ${ }^{2}$ SMCD Department, AM R\&D Gent, 9060 Zelzate, Belgium
}

\begin{abstract}
Metastable Fe-Mn alloys exhibit a non-thermoelastic martensitic transformation which is accompanied by a significant thermal effect (ca. $20 \mathrm{~J} / \mathrm{g}$ ). Among Fe-Mn alloys, the highest value of latent heat was registered in alloys with 17-18 wt. \% Mn. In this work we investigate effects of carbon (up to 0.4 wt. \%) and cold rolling (5-25\% of thickness reduction) on the latent heat and the temperature hysteresis of the martensitic transformation. Changes in chemical and phase composition are analyzed based on the goal of enthalpy maximizing. The martensite $\leftrightarrow$ austenite transitions are registered using differential scanning calorimetry and dilatometry. The phase composition is determined by means of X-ray diffraction. An effect of thermocycling is considered in connection with microstructural and enthalpy changes.
\end{abstract}

\section{Introduction}

In 1975 Enami [1] reported a weak shape memory effect in Fe-18Mn alloy. Further investigations on metastable binary Fe-Mn alloys [2] revealed that the highest value of enthalpy is obtained when manganese content amounts to $17-18 \%$ (here and thereafter the content is given in wt. \%). Jun et al. [3] studied the effect of $0.02-0.3 \%$ carbon addition in Fe-17Mn and showed that carbon decreases the Ms temperature, reduces the volume fraction of epsilon martensite and decreases the damping capacity. However addition of $0.3 \%$ carbon to Fe-17Mn- $6 \mathrm{Si}$ alloy promotes better shape recovery [4].

The transition of fcc austenite into hcp epsilon martensite phase occurs by advancing of a/ $6<112>$ Shockley partial dislocation on every second $\{111\}$ austenite plane. Depending on the stacking fault energy (SFE) of austenite, it is expected that cold rolling of metastable Fe-Mn alloy will result either in $\breve{a} \rightarrow 1$ transformation induced plasticity (TRIP), twinning induced plasticity (TWIP) or dislocation gliding in austenite [5]. Other key parameters which determine the mechanism of deformation are the critical stress needed for epsilon martensite formation and the strength of austenite. In this work we try to promote formation of stress-induced martensite by preventing dislocation gliding in austenite. Carbon was added as an interstitial element which strengthens austenite. Although carbon suppresses the $\breve{a} \rightarrow 1$ transition by decreasing the Ms temperature [3], its positive strengthening effect is more beneficial for the shape memory effect [4]. This fact stimulated the present investigation of rolled Fe-Mn-C alloys since we expect that cold rolling will form stress-induced martensite in addition to the existing thermal martensite. This is of particular interest as the bigger volume fraction of epsilon martensite can probably increase the enthalpy of transformation by analogy with the improvement of damping properties after cold rolling [3].

It is known that carbon worsens the chemical homogeneity of Fe-Mn-based solid solutions [6]. Although carbon is rather an unavoidable impurity in industrially produced iron-based alloys, its effect on the latent heat of the $\varepsilon \rightarrow \gamma$ reverse transformation (RevT) in Fe-Mn-C alloys has not been reported yet. This work is aimed to study the effects of carbon and cold rolling on the latent heat and the hysteresis of the $1 \rightarrow$ a transformation in metastable Fe-Mn-(C) alloys.

The alloys were cast using electrolytic Fe (99.95\%) and Mn (99.99\%) in an inductive furnace under an argon atmosphere. Carbon was added in the form of graphite. After solidification the ingots of ca. $20 \times 20 \times 4.5 \mathrm{~cm}^{3}$ were cut into blocks of ca. $10 \times 10 \times 4 \mathrm{~cm}^{3}$ which were then subjected to a homogenization annealing at $1523 \mathrm{~K}$ for $7200 \mathrm{~s}$. Then the blocks were hot rolled and air cooled. Samples of about $13 \times 1.5 \times 1 \mathrm{~cm}^{3}$ machined from the hot rolled blocks were subsequently annealed at $1373 \mathrm{~K}$ for $1800 \mathrm{~s}$ and water quenched. One series of the samples was used for DSC sample preparation while another group was cold rolled with 5,15 or $25 \%$ thickness reduction. The chemical composition of the three cast alloys determined using ICP-MS analysis is listed in Table 1 .

a e-mail: Mykhaylo.Murasov@mtm. kuleuven.be

This is an Open Access article distributed under the terms of the Creative Commons Attribution-Noncommercial License (http://creativecommons.org/licenses/by-nc/3.0/), which permits unrestricted use, distribution, and reproduction in any noncommercial medium, provided the original work is properly cited. 
Table 1. Chemical composition of alloys (wt. \%).

\begin{tabular}{|c|c|c|c|}
\hline Alloy designation & $\mathrm{C}$ & $\mathrm{Mn}$ & $\mathrm{Fe}$ \\
\hline Fe-18Mn & 0.003 & 18.3 & bal. \\
\hline Fe-18Mn-0.17C & 0.17 & 18.2 & bal. \\
\hline Fe-19Mn-0.25C & 0.25 & 18.7 & bal. \\
\hline Fe-21Mn-0.41C & 0.41 & 21.2 & bal. \\
\hline
\end{tabular}

The alloys were analyzed by means of differential scanning calorimetry (DSC), X-ray diffraction (XRD) and dilatometry. The XRD measurements were carried out using a Siemens D5000 diffractometer with a copper Xray source and $\theta-2 \theta$ goniometry geometry. The $2 \theta$ scanned range amounts to $40-100^{\circ}$. The calorimetry measurements were carried out using a Netsch DSC 404 calorimeter. A homogeneous protective atmosphere was provided by purging with helium at a level of $50 \mathrm{ml} \mathrm{min}^{-1}$. The heating and cooling rates were equal to $10 \mathrm{~K} \mathrm{~min}^{-}$ ${ }^{1}$. Three consecutive thermocycles between 153 and $673 \mathrm{~K}$ were applied for the materials investigated. A Bähr Dil805 dilatometer with a K-type thermocouple and liquid nitrogen cooling accessory was used for dilatometry tests. The heating and cooling rates were equal to $2 \mathrm{~K} \mathrm{~s}^{-1}$. Since the properties of Fe-Mn metastable alloys are strongly dependent on their preceding thermo-mechanical history, an index $\mathrm{N}$ [2] was introduced for comparison of DSC results. This index corresponds to the number of phase transitions induced by heating or cooling in a sample under consideration.

\section{Effect of carbon}

The transformation temperatures (TT) determined using DSC and dilatometry are listed in Table 2. According to [2], the TT in Fe-Mn alloys reach a relative steady state after seven thermocycles. Thus in our work, the experimental alloys were thermocycled using the dilatometer up to $\mathrm{N}=14$. The discrepancy in TT obtained using dilatometry and DSC is probably due to a difference in the signal registered by these techniques. It was noticed that the dilatometer is more inertial upon $\gamma \rightarrow \varepsilon$ forward transformation (FT) while DSC is slightly more inertial upon RevT. In spite of the discrepancy both techniques show the same trend in TT changes upon thermocycling. No clear transformation was detected in Fe-21Mn- $0.41 \mathrm{C}$ upon both FT and RevT. Addition of $0.17 \% \mathrm{C}$ to the base alloy in undeformed state enlarges the hysteresis of martensitic transformation by $100 \%$. The hysteresis of transformation (Af - Ms temperature interval) expands by 20 and 13\% upon the second and the third thermocycles, respectively. Each next thermocycle results in smaller expansion of hysteresis until the steady state is achieved. The latent heat upon RevT was measured using DSC. The data are listed in Table 3.

Table 2. The transformation temperatures (in K) of tested alloys.

\begin{tabular}{|c|c|c|c|c|c|c|c|c|c|c|c|c|c|c|c|}
\hline \multirow{3}{*}{$\mathrm{N}$} & \multicolumn{6}{|c|}{$\mathrm{Fe}-18.3 \mathrm{Mn}$} & \multicolumn{6}{|c|}{ Fe-18Mn-0.17C } & \multirow{2}{*}{\multicolumn{3}{|c|}{$\frac{\mathrm{Fe}-19 \mathrm{Mn}-0.25 \mathrm{C}}{\mathrm{DSC}}$}} \\
\hline & \multicolumn{3}{|c|}{$\mathrm{DSC}$} & \multicolumn{3}{|c|}{ Dilatometer } & \multicolumn{3}{|c|}{ DSC } & \multicolumn{3}{|c|}{ Dilatometer } & & & \\
\hline & Ms & As & Af & Ms & As & Af & Ms & As & Af & Ms & As & Af & Ms & As & Af \\
\hline 2 & 425 & 476 & 487 & 372 & 461 & 482 & 343 & 460 & 487 & 299 & 418 & 463 & & 433 & 480 \\
\hline 4 & 417 & 480 & 493 & 364 & 463 & 487 & 325 & 471 & 498 & 285 & 428 & 458 & - & 437 & 486 \\
\hline 6 & 411 & 484 & 497 & 360 & 464 & 489 & 320 & 474 & 510 & 281 & 434 & 470 & & 439 & 490 \\
\hline 14 & & - & & 344 & 469 & 493 & & - & & 257 & 434 & 470 & & - & \\
\hline
\end{tabular}

Table 3. Latent heat (in $\mathrm{J} / \mathrm{g}$ ) upon reverse transformation in tested alloys.

\begin{tabular}{|c|c|c|c|}
\hline $\mathrm{N}$ & Fe-18Mn & Fe-18Mn-0.17C & Fe-19Mn-0.25C \\
\hline 2 & 11.43 & 4.98 & 1.31 \\
\hline 4 & 14.95 & 8.38 & 4.93 \\
\hline 6 & 15.22 & 9.30 & 6.20 \\
\hline
\end{tabular}


The difference in enthalpy between $\mathrm{N}=4$ and 2 is about $3.5 \mathrm{~J} / \mathrm{g}$ for all the alloys. By analogy with changes in hysteresis width, the enthalpy increment becomes smaller upon subsequent thermocycles. Thus the enthalpy increment between $\mathrm{N}=6$ and 4 is about $1 \mathrm{~J} / \mathrm{g}$ for all the alloys. The absolute value of measured latent heat is decreased by $\sim 4 \mathrm{~J} / \mathrm{g}$ for every $0.1 \%$ carbon addition in the base alloy that can be explained by a rise of the SFE of austenite [5]. Among the Fe-Mn-C alloys in question the highest value of latent heat was measured in Fe-18Mn$0.17 \mathrm{C}$ upon the third thermocycle.

\section{Effect of cold rolling}

\subsection{The phase composition of rolled material determined using X-ray diffraction}

The evolution of phase composition after cold rolling was investigated using XRD. X-ray diffractograms of $\mathrm{Fe}-18 \mathrm{Mn}$ and Fe-19Mn-0.25C alloys in undeformed state and after cold rolling are presented in Fig. 1 and 2 , respectively. Hence, in undeformed state the alloys consist of austenite and epsilon martensite. A small fraction (about 5\% volume fraction) of alpha prime martensite was detected in Fe-18Mn. Cold rolling of the alloy up to $5 \%$ thickness reduction leads to an increase in intensity of the $(002) \varepsilon$ peak at the expense of the (111) $\gamma$ peak that indicates formation of stress-induced epsilon martensite from retained austenite. Heavier cold rolling causes formation of alpha prime martensite $\left(\alpha^{\prime}\right)$. According to [7] the presence of $\alpha^{\prime}$-martensite in a metastable alloy deteriorates damping and shape memory properties and therefore its content should be minimized. Cold rolling of Fe-19Mn-0.25C alloy does not result in $\alpha$-martensite formation even by $25 \%$ thickness reduction. In addition to that the diffractograms in Fig. 2 prove the formation of stress-induced epsilon martensite by cold rolling.

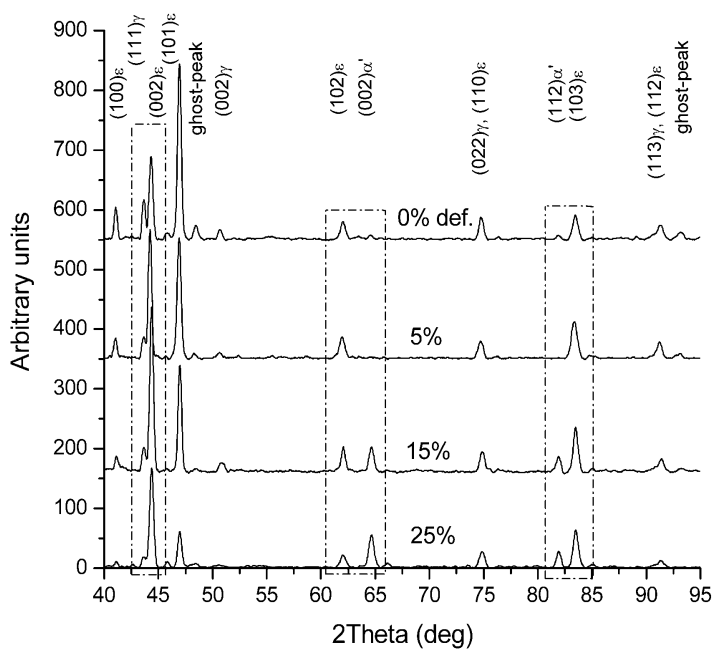

Fig 1. X-ray diffractograms of Fe-18Mn

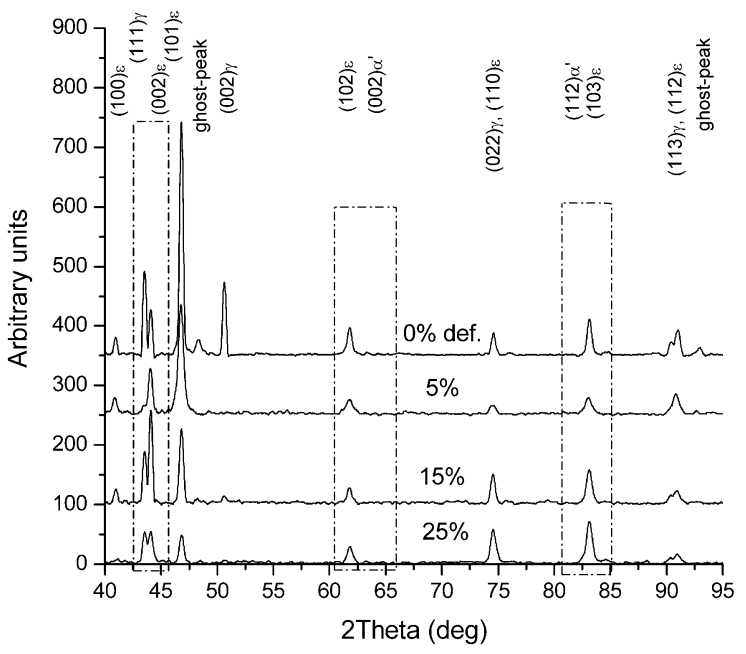

Fig 2. X-ray diffractograms of Fe-19Mn-0.25C

Effect of cold rolling on the TT and the hysteresis of transformation in Fe-18Mn-(0.17C) is summarized in Fig. 3. The hysteresis of transformation for alloys with higher carbon content was not included since their DSC peaks were too small and unclear for a correct Ms temperature determination. In Fe-18Mn-(0.17C) alloys, cold rolling causes expansion of the hysteresis of transformation. Due to addition of $0.17 \%$ carbon to the base alloy the hysteresis remains stable between 5 and 15\% thickness reduction. This effect can be explained by carbon strengthening of austenite which results in lower density of defects after deformation. The expansion of hysteresis of rolled materials occurs mainly due to an increase of Af temperature (see Fig. 3a). Hence, a lower density of defects in rolled metastable Fe-Mn-C alloy simplifies the end of RevT.

The evolution of the latent heat of the cold rolled base alloy with different carbon additives is shown in Fig. 4. These alloys experienced three consecutive thermocycles using DSC. Following trends can be seen in Fig. 4:

- Subjecting the base Fe-18Mn alloy to cold rolling with more than 5\% thickness reduction reduces the enthalpy of transformation by $50 \%$. Since the absolute error of the latent heat measurements is about $1 \mathrm{~J} / \mathrm{g}$, the enthalpy remains rather unaffected by cold rolling degree below $5 \%$ reduction.

- Cold rolling of Fe-18Mn-0.17C alloy up to $15 \%$ thickness reduction does not affect the enthalpy upon the first thermocycle and leads to a continuous decrease of enthalpy upon subsequent thermocycles. Cold rolling of carbon containing alloys with more than $15 \%$ thickness reduction reduces the enthalpy up to $0 \mathrm{~J} / \mathrm{g}$ upon $\mathrm{N}=6$.

- Although addition of $0.25 \%$ carbon to the base alloy decreases the enthalpy of transformation by suppressing FT, subsequent cold rolling up to $5 \%$ thickness reduction increases the measured latent heat 
upon $\mathrm{N}=4$ by ca. $30 \%$. Subjecting the alloy to heavier cold rolling leads to a constant decrease of the enthalpy. Thermocycling of rolled Fe-19Mn-0.25C alloy results in a decrease of the measured latent heat.

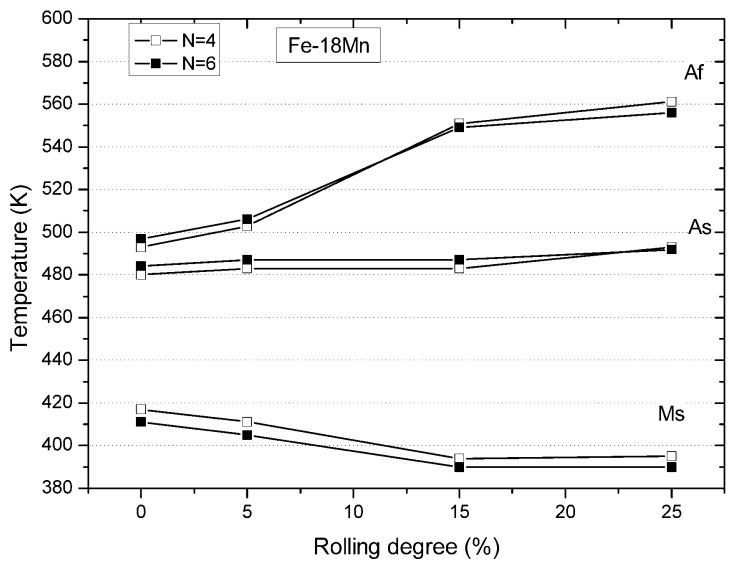

a)

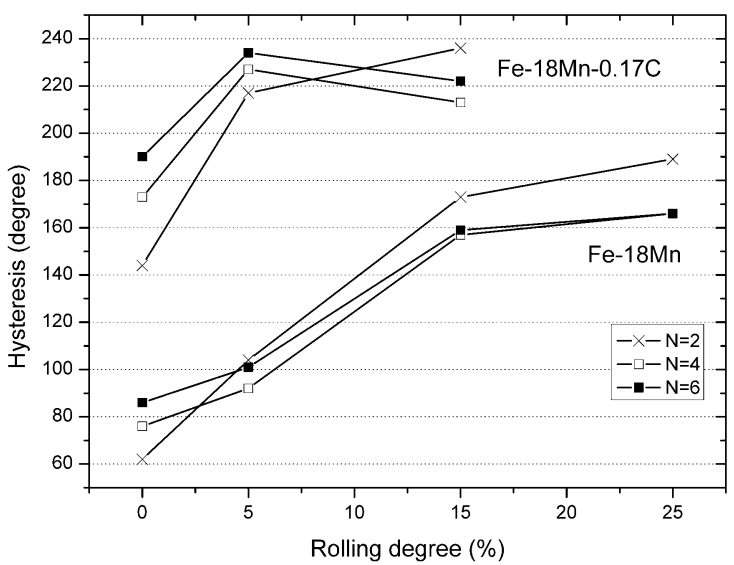

b)

Fig. 3. Effect of cold rolling on the transformation temperatures (a) and the hysteresis of transformation (b)

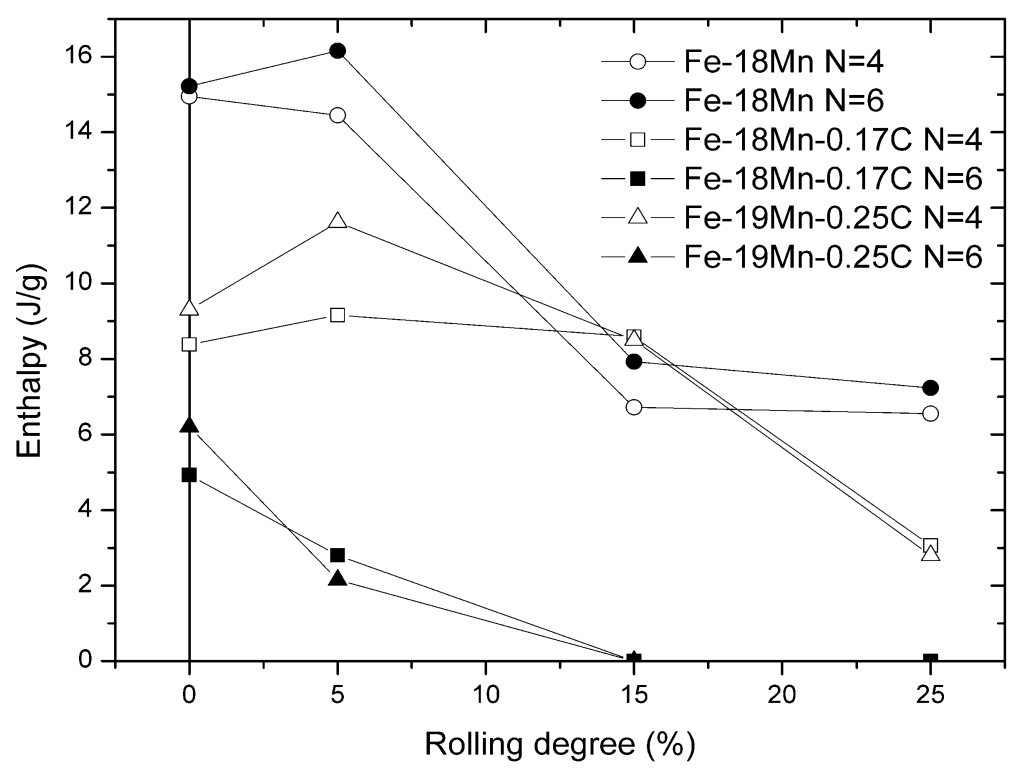

Fig. 4. Effect of cold rolling and thermocycling in the base alloy with carbon additives.

According to [3], the suppression of $\gamma \rightarrow \varepsilon$ transformation in metastable Fe-Mn alloys takes place due to lowering of the Ms temperature by carbon addition. Another important parameter that can affect the martensitic transformation is the Néél temperature of austenite [8]. The Néél temperature for the alloys in question can be calculated based on the chemical composition using formulae presented in $[9,10]$. The calculations show that an addition of $1 \% \mathrm{Mn}$ to the base alloy results in an increase of the Néél temperature by $10 \mathrm{~K}$. Carbon has a relatively small influence: addition of $0.4 \%$ carbon reduces the Néél temperature by ca. $8 \mathrm{~K}$. Based on this evidence, the effect of the Néél temperature can explain the absence of the measured latent heat in undeformed Fe-21Mn-0.4C, but not in Fe-18Mn-0.17C alloy. In addition to that carbon is a well-known austenite stabilizer which presumably decreases the driving force of the martensitic transformation when added to the base alloy. 


\section{Conclusions}

The effect of carbon, cold rolling and their superposition on the latent heat and the hysteresis of martensitic transformation were first reported for the metastable Fe-18Mn alloy. An addition of $0.17 \%$ carbon to the base Fe-18Mn alloy significantly decreases the enthalpy of transformation as a result of stacking fault energy rise of austenite which also leads to elimination of unfavourable $\alpha^{\prime}$ martensite phase. Carbon enlarges the hysteresis of transformation due to a decrease in the Ms temperature and it prevents formation of $\alpha^{\prime}$ martensite upon cold rolling even by $25 \%$ thickness reduction. This is possibly due to higher level of the stacking fault energy of austenite which results in twinning induced plasticity upon rolling.

Cold rolling of the alloys results in formation of stress-induced martensite in addition to the existing thermal martensite that decreases the enthalpy of transformation.

\section{References}

[1] K. Enami, A. Nagasawa and S. Nenno, Scripta Metallurgica 9, 941-948 (1975).

[2] P. Marinelli, A. Baruj, J. Pons, M. Sade, A. F. Guillermet and E. Cesari, Materials Science and Engineering a-Structural Materials Properties Microstructure and Processing 335, 137-146 (2002).

[3] J. H. Jun, S. H. Baik, Y. K. Lee and C. S. Choi, Scripta Materialia 39, 39-44 (1998).

[4] K. Tsuzaki, Y. Natsume, Y. Kurokawa and T. Maki, Scripta Metallurgica Et Materialia 27, 471-473 (1992).

[5] S. Allain, J. P. Chateau, O. Bouaziz, S. Migot and N. Guelton, Materials Science And Engineering A-Structural Materials Properties Microstructure And Processing 387, 158-162 (2004).

[6] V. V. Bliznuk, V. G. Gavriljuk, G. P. Kopitsa, S. V. Grigoriev and V. V. Runov, Acta Materialia 52, 4791-4799 (2004).

[7] Y. K. Lee, J. H. Jun and C. S. Choi, Isij International 37, 1023-1030 (1997).

[8] T. Hinomura, S. Nasu and Y. Tomota, J. Japan Inst. Metals 62, 635-641 (1998).

[9] S. Cotes, M. Sade and A. F. Guillermet, Metallurgical and Materials Transactions a-Physical Metallurgy and Materials Science 26, 1957-1969 (1995).

[10] Y. S. Zhang, X. Lu, X. Tian and Z. X. Qin, Materials Science and Engineering a-Structural Materials Properties Microstructure and Processing 334, 19-27 (2002). 